\title{
The Correlation of CD206, CD209, and Disease Severity in Behçet's Disease with Arthritis
}

\author{
Bunsoon Choi, ${ }^{1}$ Chang-Hee Suh, ${ }^{2}$ Hyoun-Ah Kim, ${ }^{2}$ \\ Hasan M. Sayeed, ${ }^{3}$ and Seonghyang Sohn ${ }^{1,3}$ \\ ${ }^{1}$ Department of Microbiology, Ajou University School of Medicine, Suwon, Republic of Korea \\ ${ }^{2}$ Department of Rheumatology, Ajou University School of Medicine, Suwon, Republic of Korea \\ ${ }^{3}$ Department of Biomedical Sciences, Ajou University School of Medicine, Suwon, Republic of Korea \\ Correspondence should be addressed to Seonghyang Sohn; sohnsh@ajou.ac.kr
}

Received 4 November 2016; Revised 26 January 2017; Accepted 1 February 2017; Published 9 March 2017

Academic Editor: Anshu Agrawal

Copyright (C) 2017 Bunsoon Choi et al. This is an open access article distributed under the Creative Commons Attribution License, which permits unrestricted use, distribution, and reproduction in any medium, provided the original work is properly cited.

\begin{abstract}
The purpose of this study was to clarify the role of pattern recognition receptors in Behçet's disease (BD). The frequencies of several pattern recognition receptors (CD11b, CD11c, CD32, CD206, CD209, and dectin-1) were analyzed in patients with BD by flow cytometry, and cytokine levels, interleukin- (IL-) 18, IL-23, and IL-17A, were compared in plasma. The analysis was performed in active $(n=13)$ and inactive $(n=13)$ stages of BD patients. Rheumatoid arthritis patients $(n=19)$, as a disease control, and healthy control (HC) $(n=19)$ were enrolled. The frequencies of CD11b+ and CD32+ cells were significantly increased in active BD patients compared to HC. Disease severity score was correlated to CD11c+, CD206+, and CD209+ in whole leukocytes and CD11b+, CD11c+, CD206+, CD209+, and Dectin-1+ in granulocytes. The plasma levels of IL-17A were significantly different between HC and active BD. IL-18 showed significant difference between active and inactive BD patients. From this study, we concluded the expressions of several pattern recognition receptors were correlated to the joint symptoms of BD.
\end{abstract}

\section{Introduction}

In immune dysfunction of Behçet's disease (BD), innate immunity is regarded to become more significantly involved in the pathogenesis. The important function of innate immunity is the initiation of defense against infection, such as virus, bacteria, and fungus, and linking to the adaptive immune responses [1]. Pattern recognition receptors (PRR) are proteins expressed on the cells of the innate immune system [2]. PRR can recognize pathogen-associated molecular patterns [3]. Most classes of the human pathogens are recognized by c-type lectin receptors (CLR), which is one kind of PRR [4]. CLR includes the mannose receptor (CD206), primarily present on the surface of macrophages and dendritic cells (DC), and asialoglycoprotein receptor family which includes DC-specific intercellular adhesion molecule-3-grabbing nonintegrin (CD209) and DC-associated C-type lectin-1 (Dectin1) $[5]$.

Several chronic inflammatory diseases, such as colitis, Crohn's disease, Kawasaki disease, and rheumatoid arthritis
(RA), have been reported to be significantly associated with CD206, CD209, and Dectin-1 [6-8]. However, in BD, the correlation of CLR has not been published at all except mannose-binding lectin, one kind of soluble protein of CLR [9]. Therefore, in this study, the expression of CD206, CD209, and Dectin-1 was analyzed and compared between active and inactive $\mathrm{BD}$ patients with arthritis. The frequencies of CD11b, CD11c, and CD32 were also analyzed by combination with CD206, CD209, and Dectin-1.

\section{Materials and Methods}

2.1. BD Patients. The patient population consisted of 13 patients with $\mathrm{BD}$, who presented for the first time or were monitored at the Department of Rheumatology, Ajou University Hospital. Clinical characteristics and therapeutic histories of these patients are shown in Tables 1 and 2 . According to the International Study Group for BD criteria, the presence of any two of the following symptoms, in 
TABLE 1: Clinical characteristics of the 13 patients with Behçet's disease.

\begin{tabular}{|c|c|c|c|c|c|c|c|c|c|c|c|c|c|c|}
\hline \multirow{2}{*}{ Patients } & \multirow{2}{*}{ Sex } & \multirow{2}{*}{ Age } & \multirow{2}{*}{$\mathrm{OU}$} & \multirow{2}{*}{ GU } & \multirow{2}{*}{ Arthritis } & \multirow{2}{*}{ EN } & \multicolumn{2}{|c|}{ Severity score } & \multicolumn{2}{|c|}{ Leukocyte } & \multicolumn{2}{|c|}{ ESR } & \multicolumn{2}{|c|}{ CRP } \\
\hline & & & & & & & 1st & 2nd & 1st & 2nd & 1 st & 2nd & 1st & 2nd \\
\hline 1 & $\mathrm{~F}$ & 55 & + & - & + & + & 4 & 0 & 7300 & 9500 & 95 & 15 & 4.66 & 0.19 \\
\hline 2 & $\mathrm{~F}$ & 36 & - & - & + & + & 3 & 0 & 3900 & 4300 & 57 & 40 & 0.4 & 0.17 \\
\hline 3 & $\mathrm{~F}$ & 59 & - & - & + & - & 2 & 0 & 5900 & 7200 & 21 & 14 & 0.03 & 0.03 \\
\hline 4 & $\mathrm{M}$ & 41 & - & - & + & - & 2 & 2 & 13900 & 10800 & 43 & 19 & 7.92 & 0.73 \\
\hline 5 & $\mathrm{~F}$ & 50 & - & - & + & - & 2 & 2 & 5900 & 7700 & 6 & 10 & 0.03 & 0.22 \\
\hline 6 & $\mathrm{~F}$ & 49 & + & - & + & + & 4 & 2 & 6100 & 6500 & 4 & 2 & 0.2 & 0.04 \\
\hline 7 & $\mathrm{~F}$ & 45 & + & + & + & + & 5 & 2 & 10800 & 5500 & 5 & 7 & 0.03 & 0.02 \\
\hline 8 & $\mathrm{~F}$ & 41 & + & - & + & - & 4 & 2 & 5600 & 5400 & 21 & 14 & 0.12 & 0.02 \\
\hline 9 & $\mathrm{~F}$ & 47 & - & - & + & - & 2 & 0 & 8500 & 6700 & 13 & 35 & 0.27 & 1.11 \\
\hline 10 & $\mathrm{~F}$ & 42 & + & - & + & - & 3 & 2 & 7600 & 6600 & 18 & 6 & 0.07 & 0.02 \\
\hline 11 & $\mathrm{~F}$ & 32 & - & - & + & + & 3 & 2 & 6400 & 5000 & 70 & 39 & 0.14 & 0.04 \\
\hline 12 & $\mathrm{~F}$ & 51 & + & + & + & - & 4 & 2 & 5900 & 5600 & 71 & 43 & 2.93 & 0.31 \\
\hline 13 & $\mathrm{~F}$ & 54 & - & - & + & - & 2 & 0 & 5400 & 6700 & 43 & 19 & 0.59 & 0.4 \\
\hline Average & & 46.3 & & & & & 3.07 & 1.23 & 7169.2 & 6730.8 & 35.9 & 20.4 & 1.34 & 0.25 \\
\hline SD & & 7.8 & & & & & 1.03 & 1.01 & 2634.8 & 1801.0 & 29.7 & 14.1 & 2.42 & 0.33 \\
\hline \multicolumn{7}{|l|}{$p$ value } & \multicolumn{2}{|c|}{0.00008} & \multicolumn{2}{|c|}{0.46} & \multicolumn{2}{|c|}{0.038} & \multicolumn{2}{|c|}{0.11} \\
\hline
\end{tabular}

OU: oral ulcer, GU: genital ulcer, EN: erythema nodosum, ESR: erythrocyte sedimentation rate, CRP: C-reactiveprotein, 1st: first blood sampling, 2nd: second blood sampling, SD: standard deviation.

TABLE 2: Medications during the blood sampling in Behçet's disease patients with arthritis.

\begin{tabular}{|c|c|c|c|c|c|c|c|c|c|c|c|c|c|c|}
\hline \multirow{2}{*}{ Patients } & \multicolumn{2}{|c|}{ Colchicine } & \multicolumn{2}{|c|}{ Steroid } & \multicolumn{2}{|c|}{ AZP } & \multicolumn{2}{|c|}{ Bucillamine } & \multicolumn{2}{|c|}{ HCQ } & \multicolumn{2}{|c|}{ SZP } & \multicolumn{2}{|c|}{ NSAIDs } \\
\hline & 1st & 2nd & 1st & 2nd & 1 st & 2nd & 1 st & 2nd & 1st & 2nd & 1st & 2nd & 1st & 2nd \\
\hline 1 & + & + & + & + & + & - & - & - & - & - & - & + & + & + \\
\hline 2 & - & - & - & - & + & + & - & - & - & - & + & + & - & - \\
\hline 3 & + & + & + & - & - & - & - & - & - & - & + & + & + & + \\
\hline 4 & + & + & + & + & - & + & + & + & - & - & - & - & + & + \\
\hline 5 & + & + & - & + & - & - & - & - & - & - & + & + & - & - \\
\hline 6 & + & + & + & - & - & - & - & - & + & + & - & - & + & + \\
\hline 7 & + & + & + & + & - & - & - & - & + & + & + & + & + & + \\
\hline 8 & + & + & + & - & - & - & - & + & - & - & + & - & + & - \\
\hline 9 & + & + & + & + & - & - & - & - & + & + & - & - & + & + \\
\hline 10 & + & + & + & + & - & - & - & - & + & + & - & - & + & - \\
\hline 11 & - & - & + & + & + & + & - & - & - & - & - & - & + & + \\
\hline 12 & + & + & + & + & - & - & - & - & - & - & + & + & + & + \\
\hline 13 & + & + & + & + & - & - & - & - & + & + & - & - & + & - \\
\hline
\end{tabular}

AZP: azathioprine, HCQ: hydroxychloroquine, SZP: sulphasalazine, NSAIDs: nonsteroidal anti-inflammatory drugs.

addition to recurrent oral ulcerations, is considered to be sufficient for a BD diagnosis: recurrent genital ulceration, uveitis, large-vessel vasculitis, cutaneous erythema nodosum, arthritis, and/or a positive pathergy test. The disease severity score was followed by Behçet's disease current activity form 2006 (http://www.behcetdiseasesociety.org/behcetwsData/ Uploads/files/BehcetsDiseaseActivityForm.pdf). The active $\mathrm{BD}$ patients with arthritis $(n=13$, male 1 , female 12 , $46.3 \pm 7.8$ years) were enrolled and treated with adding or increasing corticosteroid or nonsteroidal anti-inflammatory drugs. Informed consent was obtained from patients prior to enrollment into the study. The healthy control (HC) group ( $n=19,37.7 \pm 15.2$ years) consisted of 6 male and 13 female participants. Blood sampling was done initially (active stage) and the follow-up after improving joint symptoms (inactive stage). Included disease control was patients with RA ( $n=19$, $30.4 \pm 10.1$ years). The medication for RA patients is shown in Supplementary Data (s-Table 1, in Supplementary Material available online at https://doi.org/10.1155/2017/7539529). This study was approved by the Institutional Review Board (IRB number BMR-SMP-13-398).

2.2. Flow Cytometric Analysis for Surface Markers. Collected peripheral blood mononuclear cells (PBMC) were treated with Ammonium-Chloride-Potassium solution for lysis of red blood cell and washed with buffered saline, after which, 
$1 \times 10^{6}$ cells in each tube were incubated with allophycocyanin (APC) labeled anti-CD4 (Catalog number 17-004942, eBiosciences), fluorescein isothiocyanate (FITC) labeled anti-CD11b (Catalog number 11-0118-42, eBiosciences), PECy7 labeled anti-CD11c (Catalog number 25-0116-41, eBiosciences), APC labeled anti-CD32 (Catalog number 17-032942, eBiosciences), PE labeled anti-CD209 (Catalog number 12-2099-42, eBiosciences), PerCP labeled anti-dectin1 (Catalog number 1-46-9856-42, eBiosciences, San Diego, CA, USA), FITC labeled anti-CD8 (Catalog number 557085, BD Bioscience), and PE-Cy5 labeled anti-CD206 (Catalog number 551136, BD Pharmingen), for 30 minutes at $4^{\circ} \mathrm{C}$. Same colors labeled antibodies were applied separately in different tubes. Isotype controls were applied also. The stained cells were then washed with buffered saline and analyzed by using a flow cytometer (FACSAria III; Becton Dickinson, San Jose, CA, USA) with $\times 10,000$ cells. The fluorescenceactivated cell sorting data was based on the gating in whole cells, granulocytes, monocytes, and lymphocytes and then applied to analyze for specific markers in gated populations. The data was repeatedly analyzed in triplicate.

2.3. Cytokine Assay. Peripheral blood was extracted in ethylenediaminetetraacetic acid containing test tubes and centrifuged at 3,500 rpm for $5 \mathrm{~min}$ at room temperature. The supernatant was stored at $-80^{\circ} \mathrm{C}$ until required. Interleukin(IL-) 18 (Catalog number BMS267/2CE, eBiosciences), IL-23 (Catalog number 88-7237-22, eBiosciences), and IL-17A (Catalog number BMS2017, eBiosciences) levels were measured in plasma using commercial enzyme-linked immunosorbent assay kits according to the manufacturer's instructions. For ELISA analysis, each sample was applied in duplicate wells and three times in different ELISA plates.

2.4. Statistical Analysis. All data shown represent the mean \pm standard deviation. Statistical analysis of patients' data was performed using the Kruskal-Wallis Test and Bonferroni correction. Differences in frequencies of several cellular markers were determined using the Mann-Whitney $U$ test. Correlations between levels and disease activity markers were evaluated with Spearman's correlation test. Statistical analyses were performed using SPSS for Windows software (ver. 23.0; IBM Corp., Armonk, NY, USA). A $p$ value $<0.05$ was considered to indicate statistical significance.

\section{Results}

3.1. Clinical Characteristics of the Patients. Clinical characteristics of the 13 patients with $\mathrm{BD}$ are summarized in Table 1. Blood sampling was performed twice at active stage of disease with arthritis (1st) and inactive stage without symptoms after medication (2nd). The disease severity scores and erythrocyte sedimentation rate (ESR) were significantly downregulated at 2 nd sampling compared to the 1st sampling $(p<0.001,0.038$ resp.). The levels of C-reactive protein (CRP) were also downregulated, but not significant. Table 2 shows the medication list at the time of blood sampling. Colchicine was used in 11 patients (84.6\%), sulfasalazine in
6 patients (46.2\%), and azathioprine in 3 patients (23.1\%). And nonsteroidal anti-inflammatory drugs were used in 11 patients (84.6\%).

3.2. The Frequencies of the PRRs on PBMC of BD Patients. The frequencies of CD11b, CD11c, CD32, CD206, CD209, and Dectin-1 positive cells were analyzed on PBMC by flow cytometry after surface staining with antibodies. The frequencies of CD11b+ cells from whole leukocytes were significantly higher in patients with active BD $(68.9 \pm 11.2 \%)$ than in RA (55.6 $\pm 17.3 \%, p=0.05)$ or HC $(50.5 \pm 12.0 \%$, $p=0.0008)$. However, patients with inactive $\mathrm{BD}(66.4 \pm$ $16.7 \%)$ showed similar frequencies to those with active $\mathrm{BD}$ (Figure 1(a)). The frequencies of CD11c+ cells in whole leukocytes were not significantly different among active BD, RA, and HC. After treatment, the frequencies of CDllct cells were decreased from $10.6 \pm 3.0 \%$ in active BD to $7.1 \pm$ $3.8 \%$ in inactive $\mathrm{BD}$. CD32+ cells were significantly higher in active $\mathrm{BD}(66.1 \pm 10.1 \%)$ than $\mathrm{HC}(51.3 \pm 13.9 \%, p=$ $0.002)$ or RA $(57.3 \pm 16.9 \%)$. The differences between active $\mathrm{BD}$ and inactive $\mathrm{BD}$ for $\mathrm{CD} 32+$ cells were not significant (Figure 1(a)). The frequencies of CD206+ cells in whole leukocytes were downregulated to $14.5 \pm 8.6 \%$ after treatment (inactive $\mathrm{BD}$ ) compared to $23.0 \pm 8.4 \%$ in active $\mathrm{BD}$, even though not significant. In monocyte gating, the frequencies of CD206+ were significantly different between active BD $(57.9 \pm 9.4 \%)$ and inactive BD $(41.0 \pm 10.6 \%, p=0.005)$. Also monocytes CD206+ in active BD was significantly high than HC $(48.8 \pm 10.5 \%, p=0.019)$ (Figure 1(b)). The frequencies of CD209+ cells were significantly higher in active $\mathrm{BD}$ than inactive $\mathrm{BD}$ in whole leukocytes $(2.4 \pm 1.5 \%$ versus $0.8 \pm 0.8 \%, p=0.007)$. The frequencies of CD209+ cells were significantly decreased in inactive $\mathrm{BD}$ compared to active $\mathrm{BD}$ in monocytes $(5.1 \pm 4.1 \%$ versus $1.0 \pm 0.7 \%$, $p=0.05$ ) (Figure $1(\mathrm{c})$ ). The frequencies of Dectin-1+ cells in granulocytes were significantly lower in inactive BD (14.3 \pm $8.0 \%)$ than HC $(23.7 \pm 8.4 \%, p=0.003)$ (Figure $1(\mathrm{~d})$ ).

Double positive cell frequencies were also analyzed (Figure 2). CD11b $+\mathrm{CD} 206+$ cells were significantly higher in active $\mathrm{BD}(18.5 \pm 6.1 \%)$ than inactive $\mathrm{BD}(11.6 \pm 5.7 \%, p=$ $0.008)$ in whole leukocytes and in monocytes $(46.0 \pm 9.7 \%$ versus $35.3 \pm 10.1 \%, p=0.008$ ) (Figure $2(\mathrm{a})$ ). CD11b+CD32+ cells were significantly higher in active $\mathrm{BD}(62.7 \pm 11.0 \%)$ than HC $(44.6 \pm 14.0 \%, p=0.0001)$ in whole leukocytes and in granulocytes $(95.8 \pm 2.4 \%$ versus $83.2 \pm 13.2 \%$, $p=0.004)$. However, these cells were not different between active BD $(62.7 \pm 11.0 \%)$ and inactive BD $(63.9 \pm 17.4 \%)$ in whole leukocytes. In monocytes, active $\mathrm{BD}$ and inactive $\mathrm{BD}$ were significantly higher than HC $(p=0.0019$ and $p=0.002$, resp.) (Figure 2(b)). CD11b+Dectin-1+ cells were lower in inactive BD $(13.7 \pm 8.8 \%)$ than $\mathrm{HC}(22.3 \pm$ 9.4\%) in granulocytes (Figure 2(c)). CD1lc+CD206+ cells were significantly lower in inactive $\mathrm{BD}(1.9 \pm 1.7 \%)$ than $\mathrm{HC}$ $(4.1 \pm 2.4 \%, p=0.01)$ in whole cells and in granulocytes $(1.7 \pm 2.4 \%$ versus $5.6 \pm 4.2 \%, p=0.01)$ (Figure $2(\mathrm{~d})$ ). $\mathrm{CD} 11 \mathrm{c}+\mathrm{CD} 32+$ were higher in active $\mathrm{BD}(9.1 \pm 2.3 \%)$ than $\mathrm{HC}(6.8 \pm 2.4 \%, p=0.01)$ in whole leukocytes. There was no difference in the frequencies of $\mathrm{CD} 11 \mathrm{c}+\mathrm{CD} 32+$ between active and inactive BD (Figure 2(e)). CD1lc+Dectin-1+ cells were 

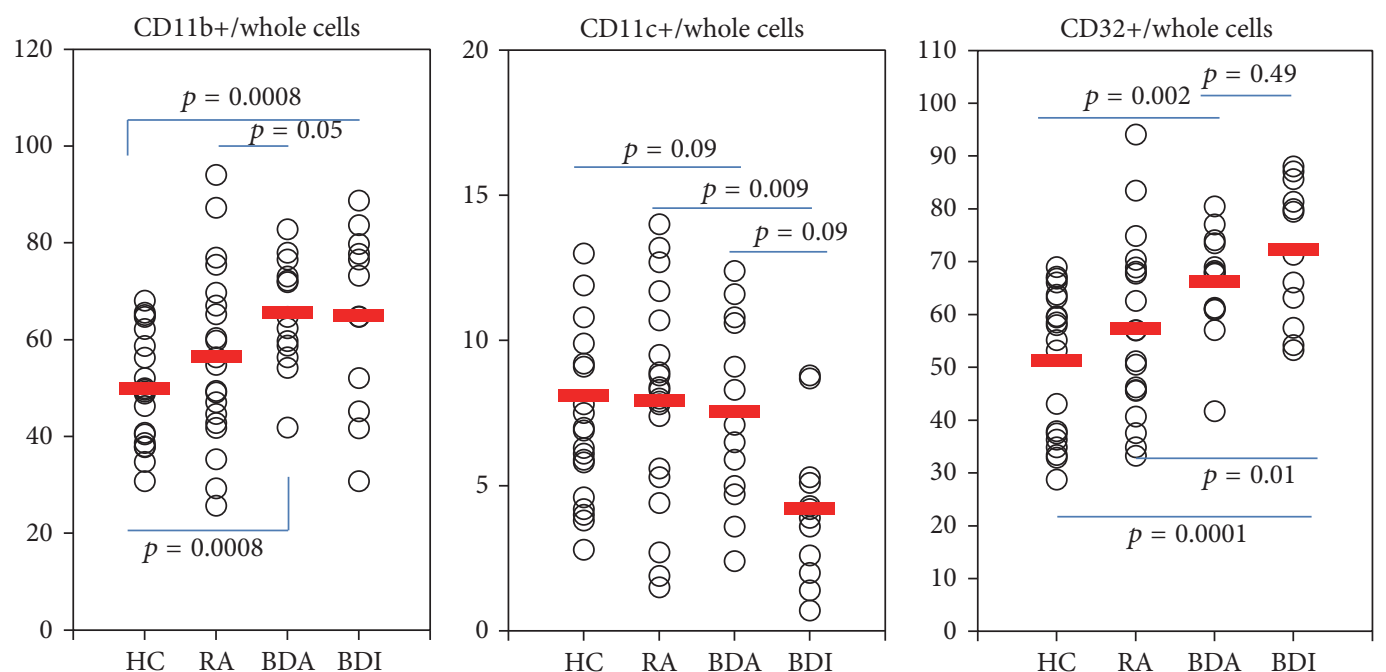

(a)
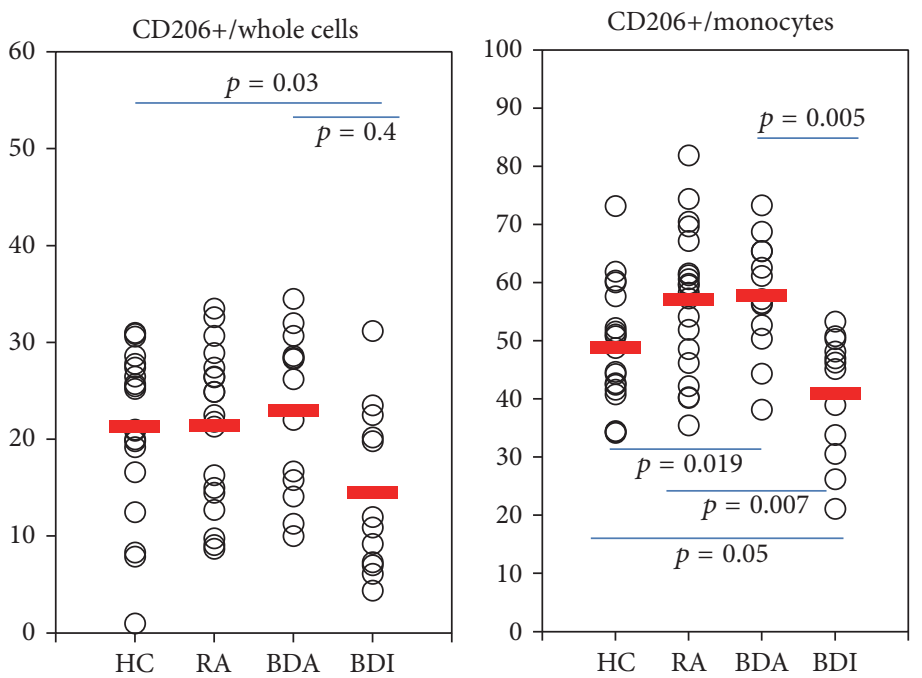

(b)
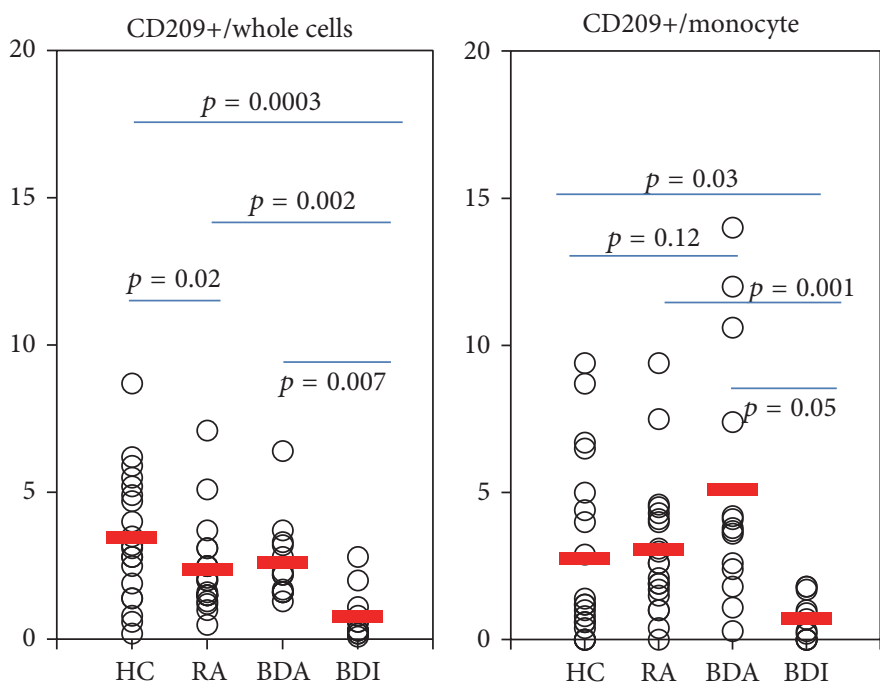

(c)

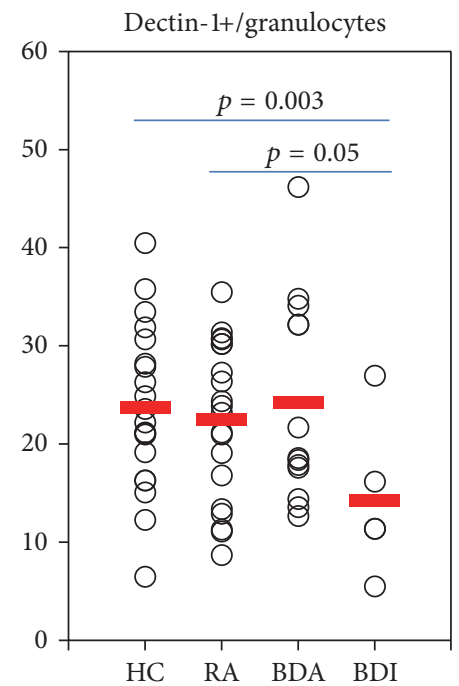

(d)

Figure 1: The frequencies of CD11b, CD11c, CD32, CD206, CD209, and dectin-1 positive cells in patients with active Behçet's disease (BDA), inactive BD (BDI), rheumatoid arthritis (RA), and healthy control (HC). The frequencies of CD11b, CD11c, and CD32 positive cells were analyzed in whole leukocytes. The frequencies of CD206, CD209, and dectin-1 positive cells were analyzed in whole leukocytes, granulocytes, and monocytes populations. 

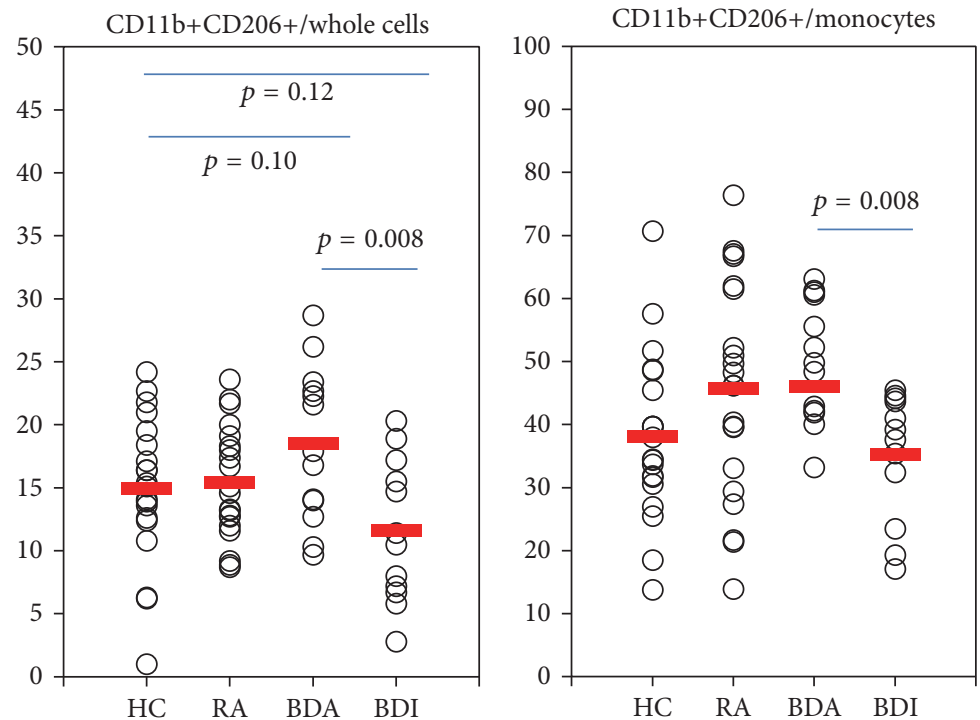

(a)
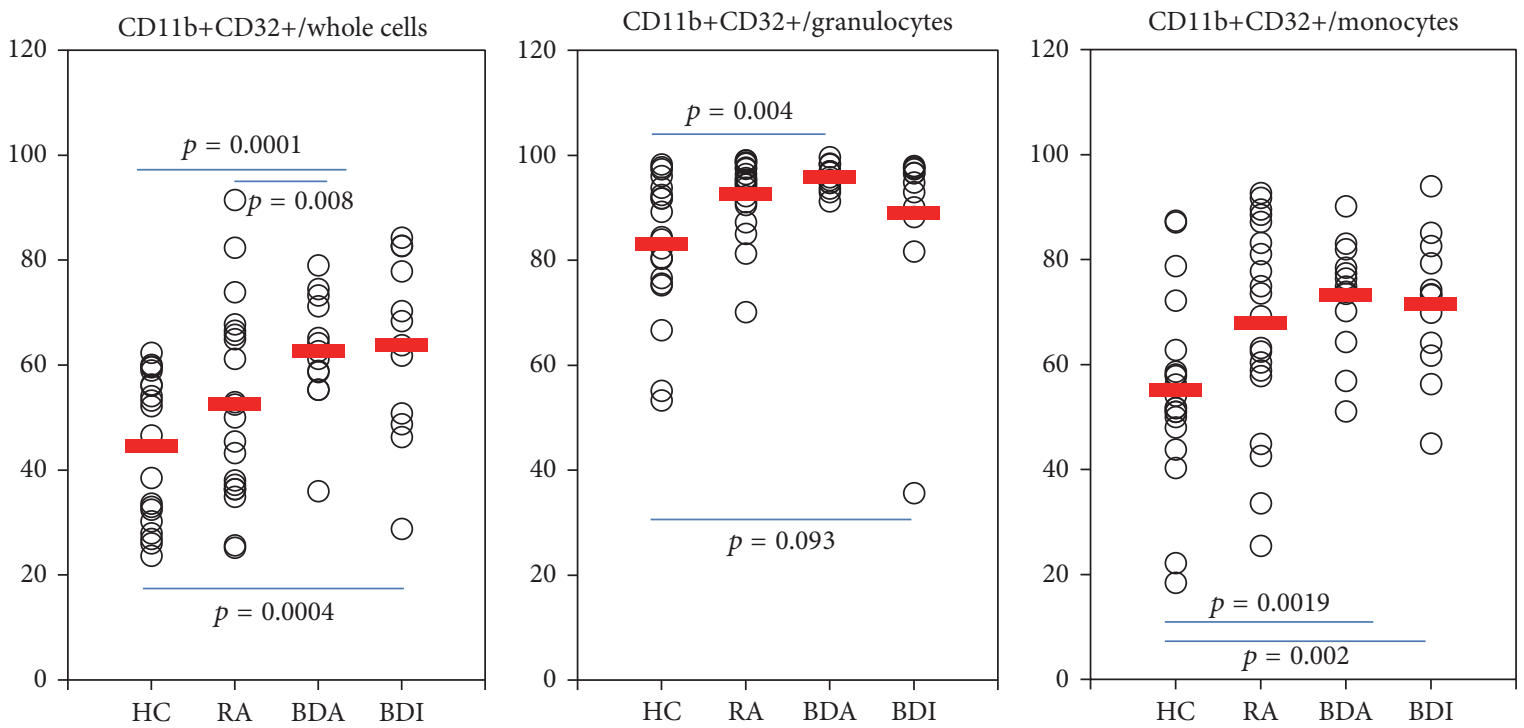

(b)

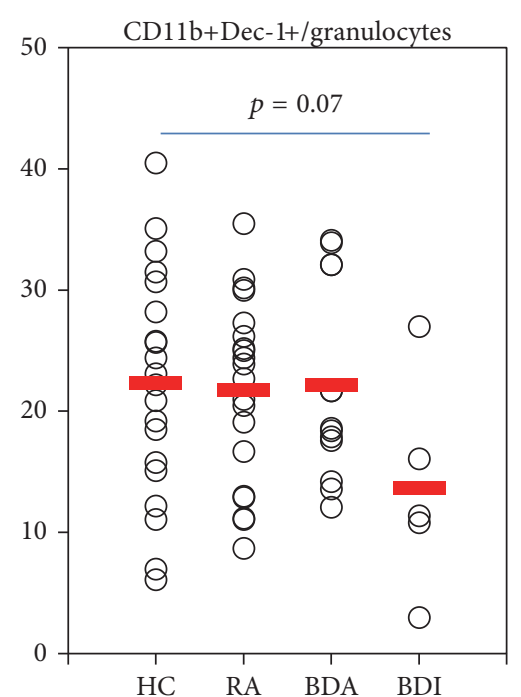

(c)
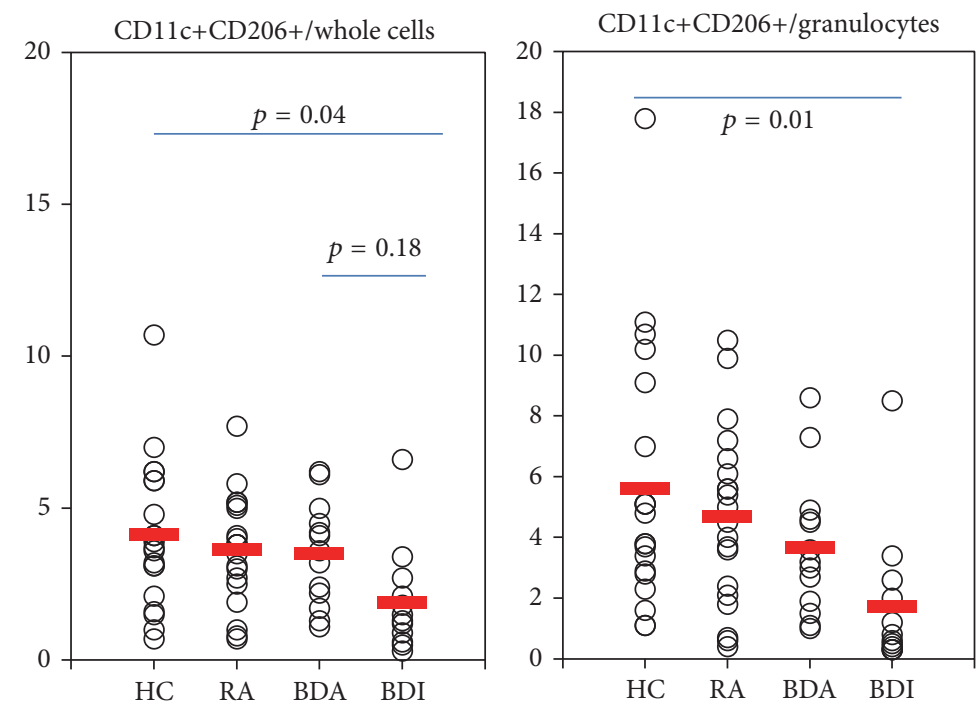

(d)

Figure 2: Continued. 


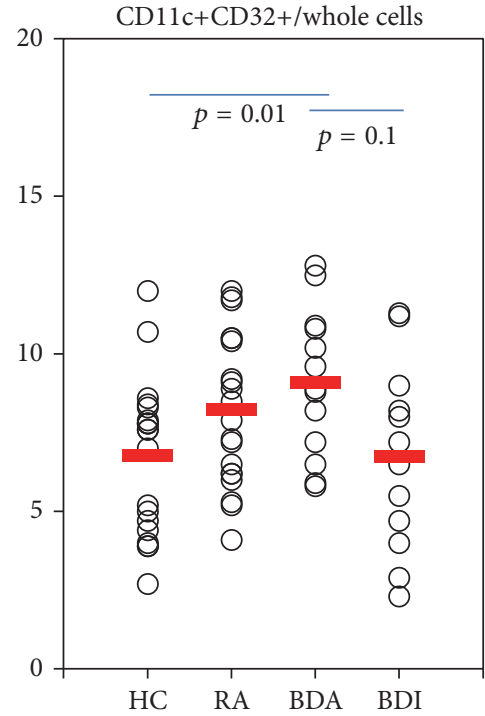

(e)
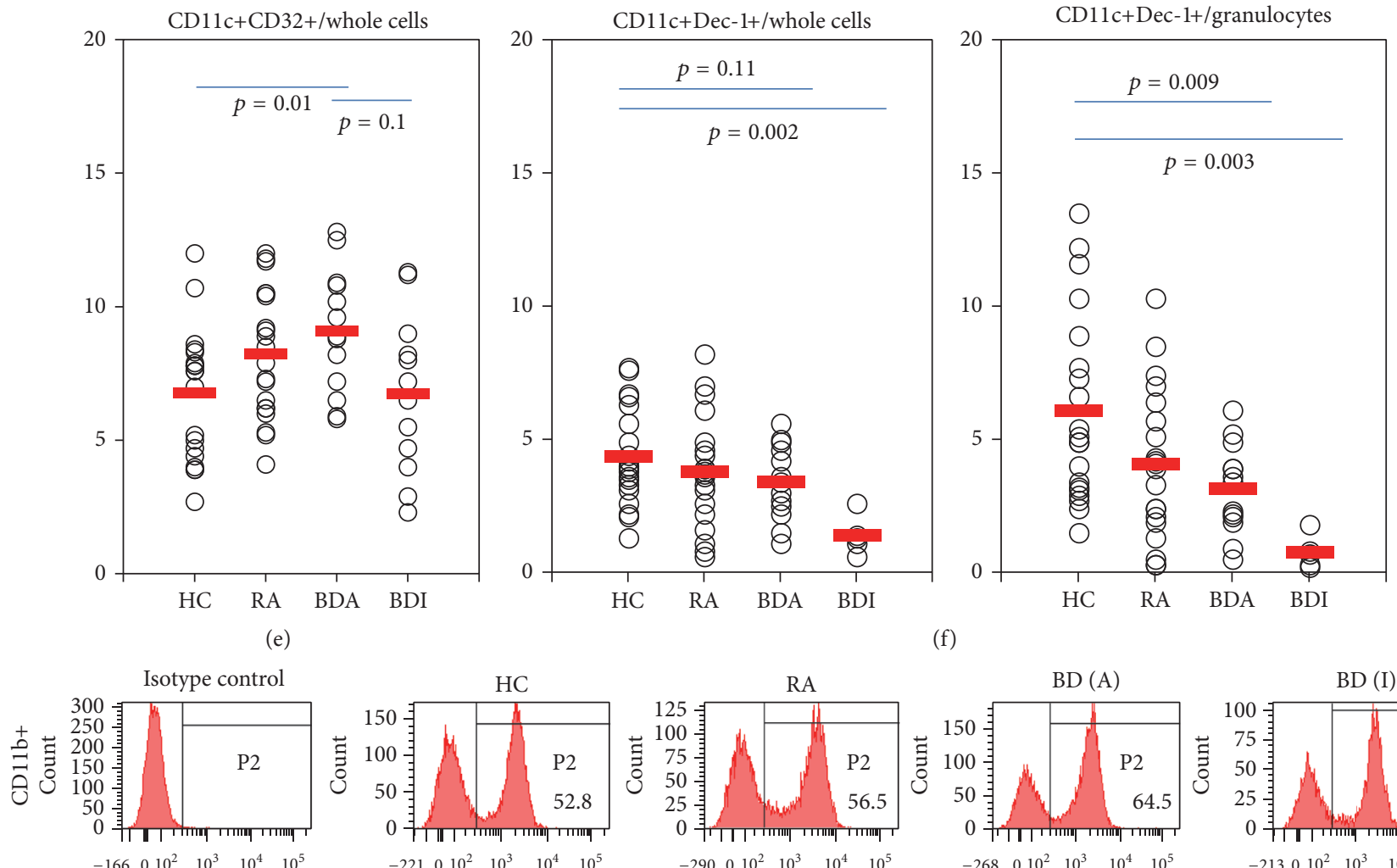

(f)
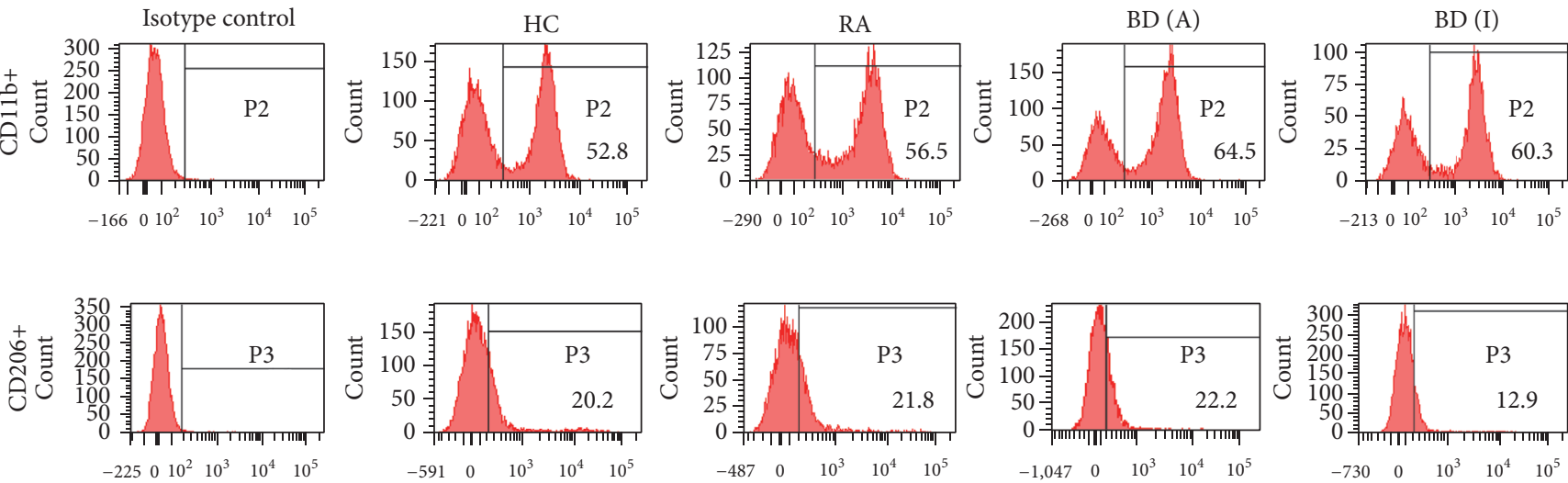

(g)

FIGURE 2: The frequencies of double positive cells in patients with active Behçet's disease (BDA), inactive BD (BDI), rheumatoid arthritis (RA), and healthy control (HC). CD11b+CD206+, CD11b+CD32+, CD11b+Dectin-1+, CD11c+CD206+, CD11c+CD32+, and CD11c+Dectin$1+$ cells were analyzed in whole leukocytes, granulocytes, and monocyte (a-f). (g) Representative histograms of CD11b+ and CD206+ cells in $\mathrm{HC}, \mathrm{RA}, \mathrm{BDA}$, and BDI.

lower in inactive $\mathrm{BD}(1.4 \pm 0.7 \%)$ than $\mathrm{HC}(4.4 \pm 1.8 \%, p=$ $0.002)$ in whole leukocytes and in granulocytes $(0.7 \pm 0.6 \%$ versus $6.1 \pm 3.6 \%, p=0.003$ ) (Figure $2(\mathrm{f})$ ). Figure $2(\mathrm{~g}$ ) shows the representative histograms of fluorescence-activated cell sorting analysis. Table 3 shows significantly different frequencies of PRR between active and inactive BD presented. Not significantly different frequencies of PRR between active and inactive BD showed in Supplementary Figure (s-Figure 1).

3.3. The Levels of IL-18, IL-23, and IL-17A in Plasma of BD Patients. Figure 3 shows plasma levels of IL-18, IL-23, and IL$17 \mathrm{~A}$ in active and inactive BD patients, RA patients, and HC. After treatment, the expression levels of IL-18 increased to $462.3 \pm 148.0 \mathrm{pg} / \mathrm{mL}$ in inactive BD from $260.1 \pm 132.5 \mathrm{pg} / \mathrm{mL}$ in active $\mathrm{BD}(p=0.007)$. IL-23 levels were not significantly different between active BD $(82.6 \pm 43.7 \mathrm{pg} / \mathrm{mL})$ and inactive BD $(87.4 \pm 51.7 \mathrm{pg} / \mathrm{mL})$. IL-17A levels were also similar between active $\mathrm{BD}(17.0 \pm 3.5 \mathrm{pg} / \mathrm{mL})$ and inactive $\mathrm{BD}$ $(18.8 \pm 5.2 \mathrm{pg} / \mathrm{mL}$ ) (Figure 3(a)). Even though the average levels of IL-23 and IL-17A from all enrolled patients did not change much after treatment, the levels of each individual patient were increased or decreased as shown in Figure 3(b). Figure 3(c) shows three cytokine levels of each individual patient analyzed before and after treatment. The levels of cytokines were not changed in the same direction after improvement of patients.

3.4. The Correlations between Disease Activity Markers and Frequencies of PRR Expressing Cells in BD Patients. The correlation between disease severity score and PRR, such as CD11b in granulocytes $(r=0.504, p=0.009)$; CD1lc in whole leukocytes $(r=0.485, p=0.012)$, granulocytes $(r=0.427, p=0.03)$, and lymphocytes $(r=0.649, p=$ $0.001)$; CD206 in whole leukocytes $(r=0.412, p=0.036)$, 

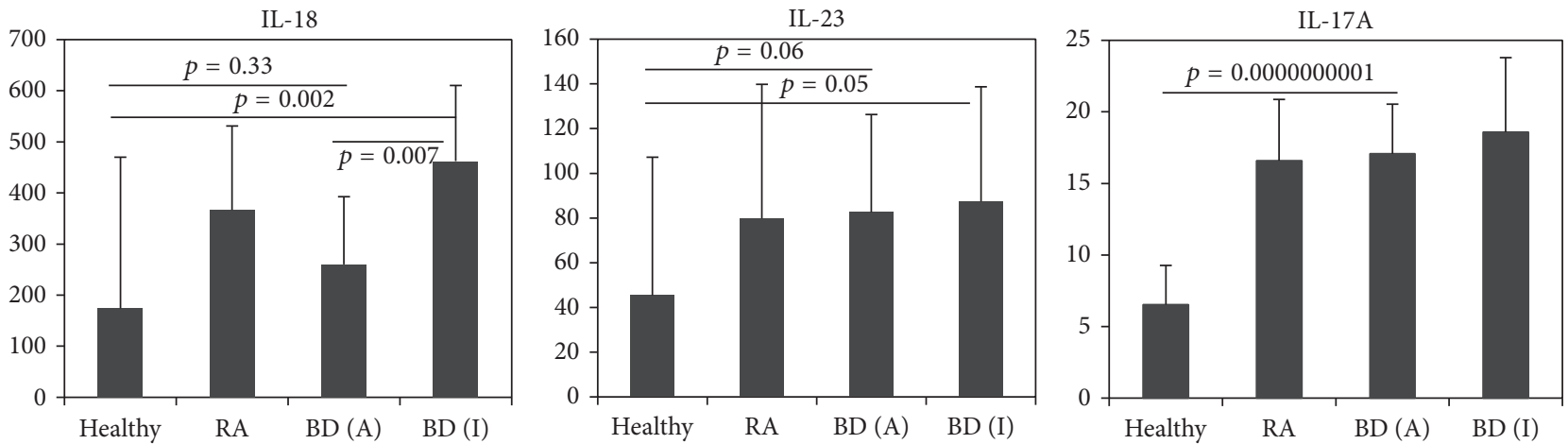

(a)
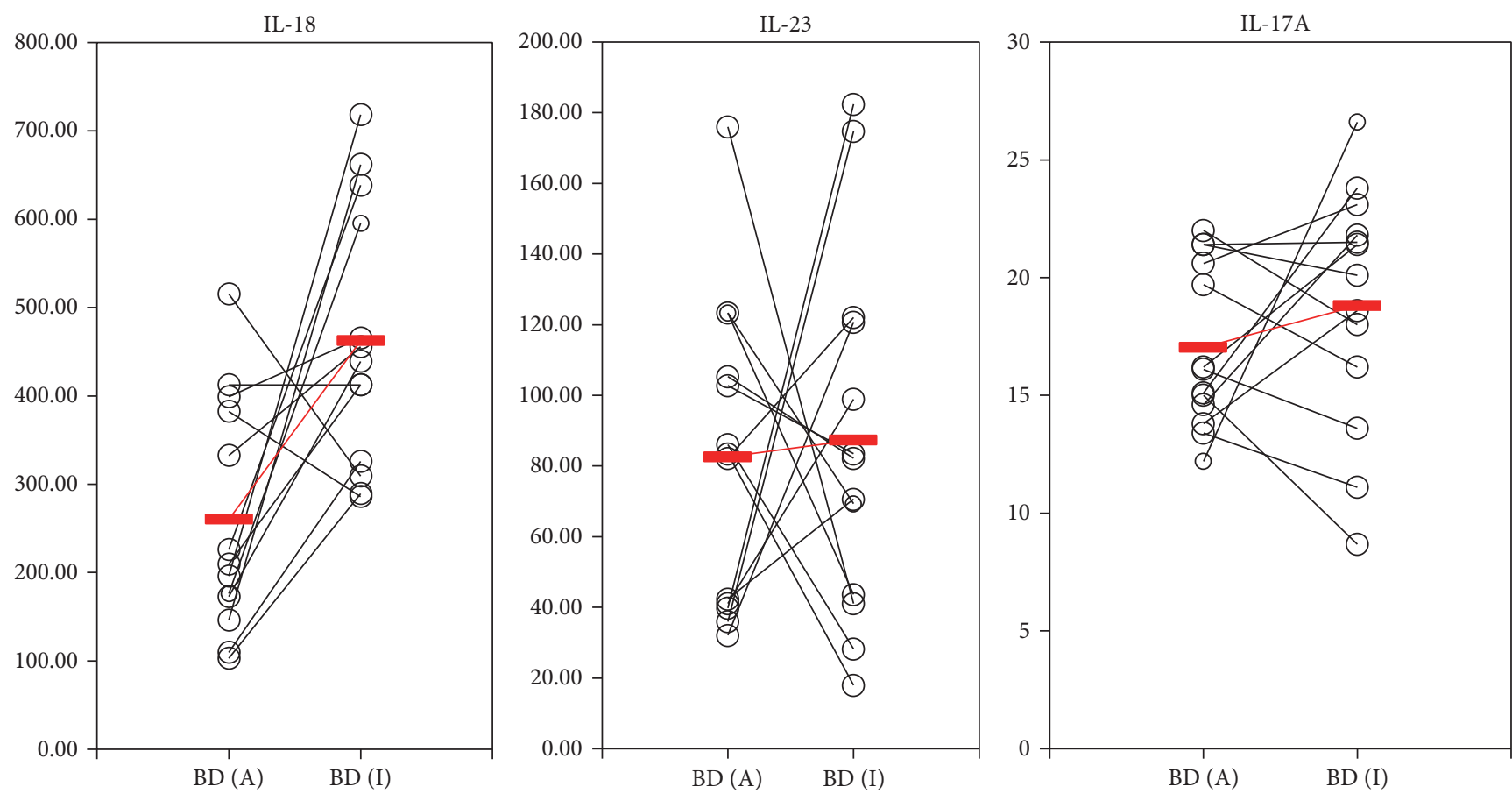

(b)

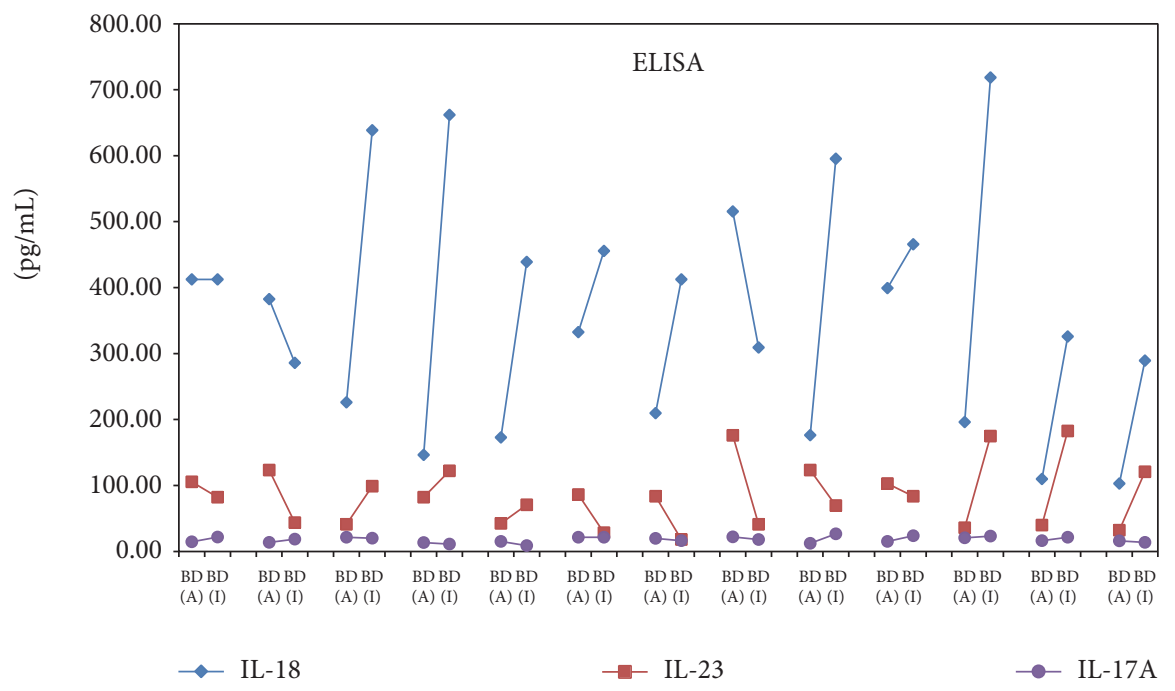

(c)

Figure 3: (a) Cytokine, IL-18, IL-23, and IL-17A expressions by enzyme-linked immunosorbent assay (ELISA) analysis in plasma of patients with active $\mathrm{BD}(\mathrm{BDA})$, inactive $\mathrm{BD}(\mathrm{BDI})$, rheumatoid arthritis (RA), and healthy control (HC). (b) The change of cytokine expression between with BDA and BDI in individual patients. 
TABLE 3: The significant changes of PRR between active and inactive Behçet's disease patients.

\begin{tabular}{lcccc}
\hline Markers & Cell population & Active BD & Inactive BD & $p$ value \\
\hline CD206+ & Monocyte & $57.9 \pm 9.4$ & $41.0 \pm 10.6$ & 0.005 \\
CD209+ & Whole leukocyte & $2.4 \pm 1.5$ & $0.8 \pm 0.8$ & 0.007 \\
CD209+ & Monocyte & $5.1 \pm 4.1$ & $1.0 \pm 0.7$ & 0.05 \\
CD11b+CD206+ & Whole leukocyte & $18.5 \pm 6.1$ & $11.6 \pm 5.7$ & 0.008 \\
CD11b+CD206+ & Monocyte & $46.0 \pm 9.7$ & $35.3 \pm 10.1$ & 0.008 \\
\hline
\end{tabular}

granulocytes $(r=0.438, p=0.025)$, monocytes $(r=0.509$, $p=0.008)$, and lymphocytes $(r=0.518, p=0.007)$; CD209 in whole leukocytes $(r=0.642, p=0.001)$, granulocytes $(r=0.48, p=0.013)$, monocytes $(r=0.615, p=0.001)$, and lymphocytes $(r=0.584, p=0.002)$; and Dectin-1 in granulocytes $(r=0.46, p=0.047)$ and lymphocytes $(r=0.668, p=0.002)$ showed significance. The plasma levels of IL-17A also showed significant correlations to CD206 in lymphocytes $(r=-0.409, p=0.038)$; CD209 in whole leukocytes $(r=-0.5, p=0.009)$, granulocytes $(r=-0.512$, $p=0.008)$, monocytes $(r=-0.52, p=0.006)$, and lymphocytes $(r=-0.477, p=0.014)$ (Table 4$)$. Other disease activity markers, such as leukocyte, ESR, CRP, cytokine IL-23, and IL-18 did not show a significant correlation.

\subsection{Correlation between the Frequencies of Each PRR Marker} in BD Patients. The correlation analysis was also applied to each surface marker of PRR in whole leukocytes (Table 5). The frequencies of CD11b were correlated to the frequencies of CD32 $(r=0.896, p<0.001)$. The frequencies of CD11c were correlated to the frequencies of CD206 ( $r=0.83, p<$ $0.001)$ and CD209 $(r=0.677, p<0.001)$. The frequencies of CD32 were negatively correlated with the frequencies of CD206 $(r=-0.439, p=0.025)$. The frequencies of CD206 were correlated positively with the frequencies of CD209 $(r=$ 0.679, $p<0.001)$ and Dectin-1 $(r=0.801, p=0.001)$.

\section{Discussion}

This study has presented the significantly different expression levels of the frequencies for PRR between BD patients and HC. The frequencies of CD11b, CD11c, CD32, CD206, CD209, and Dectin-1 positive cells were differently expressed on whole leukocytes, granulocytes, monocytes, or lymphocytes among active $\mathrm{BD}$, inactive $\mathrm{BD}$, and $\mathrm{HC}$. The frequencies of CD206 and CD209 showed significant correlation with plasma levels of IL-17A. Specifically, the frequencies of CD11b, CD11c, CD32, CD206, CD209, and Dectin-1 positive cells were correlated significantly to the disease severity score of BD patients.

It is well known PRR plays critical roles in pathogen recognition and linking to the generation of adaptive immunity [10]. Toll-like receptor, a family of PRR, has been revealed in $\mathrm{BD}$ [11-14]. However, C-type lectin receptors, another family of PRR, CD206, CD209, and Dectin-1, can be found in a few cases in BD patients until now. Downregulation/deficiency of C-type lectin domain family 12, member A (CLEC12A), a C-type lectin-like pattern recognition receptor, is associated with hyperinflammatory responses. Patients with severe forms of Behçet's disease underexpress CLEC12A with respect to patients with mild forms of the disease [15]. Mannose-binding lectin gene-2 polymorphisms and serum mannose-binding lectin levels are associated with the production of high levels of MBL in Behçet's disease. Dectin-1 is upregulated on immune cells such as macrophages and neutrophils in inflammatory bowel disease [16]. Dectin-1 plays a critical role in experimental autoimmune uveitis development by Freund's Complete Adjuvant/interphotoreceptor retinoid-binding protein mixture at the induction phase. Uveitis is one of the major symptoms of BD in patients. Anti-dectin-1 antibody treatment can prevent the development of experimental autoimmune uveitis [17]. In BD patients, the correlation with Dectin-1 was not reported. CD209 promote CD3-activated $\mathrm{T}$ cells to produce IL- 2 and strengthen the interaction of $\mathrm{T}$ cell receptor-antigen presenting cell and enhance immune response [18]. CD209 was reported in secondary progressive multiple sclerosis [19] and Crohn's disease [20]; however, the correlation was not studied in BD. Our study showed the correlation of several PRR (CD11b, CD11c, CD32, CD206, CD209, and dectin-1) in the pathogenesis of BD.

The mean fluorescence intensity of CD11b on granulocytes was higher in $\mathrm{BD}$ patients with heart diastolic dysfunction than those of controls [21]. The mean fluorescence intensity of CD11b in CD8 bright cells was also higher in BD patients with uveitis than controls or $\mathrm{BD}$ without uveitis [22]. Similar to previous reports, our study showed that BD patients with arthritis had higher frequencies of CD11b+ cells than disease control RA patients and the HC. After improvement with treatment, the frequencies of CD11b+ cells of inactive BD were not changed.

Single nucleotide polymorphisms of CD11c have been suggested as susceptibility loci in Korean BD patients with cutaneous symptoms [23] and in Chinese Han population BD patients with eye symptoms [24]. The frequencies and protein expression levels of CD11c+ cells were significantly increased in the CD4+ and CD8+ cell populations of active BD patients with cutaneous symptoms compared to those in the HC. In BD patients with arthritis, from our study, CD11c+ cells showed similar frequencies to $\mathrm{HC}$. Inactive BD patients showed downregulation of CD11c+ cells compared to active BD patients though the difference was not significant. This difference can be from the different immune responses between $\mathrm{BD}$ cutaneous symptoms and $\mathrm{BD}$ arthritic symptoms, even though $20 \%$ of enrolled patients have both cutaneous and arthritic symptoms in each report. 


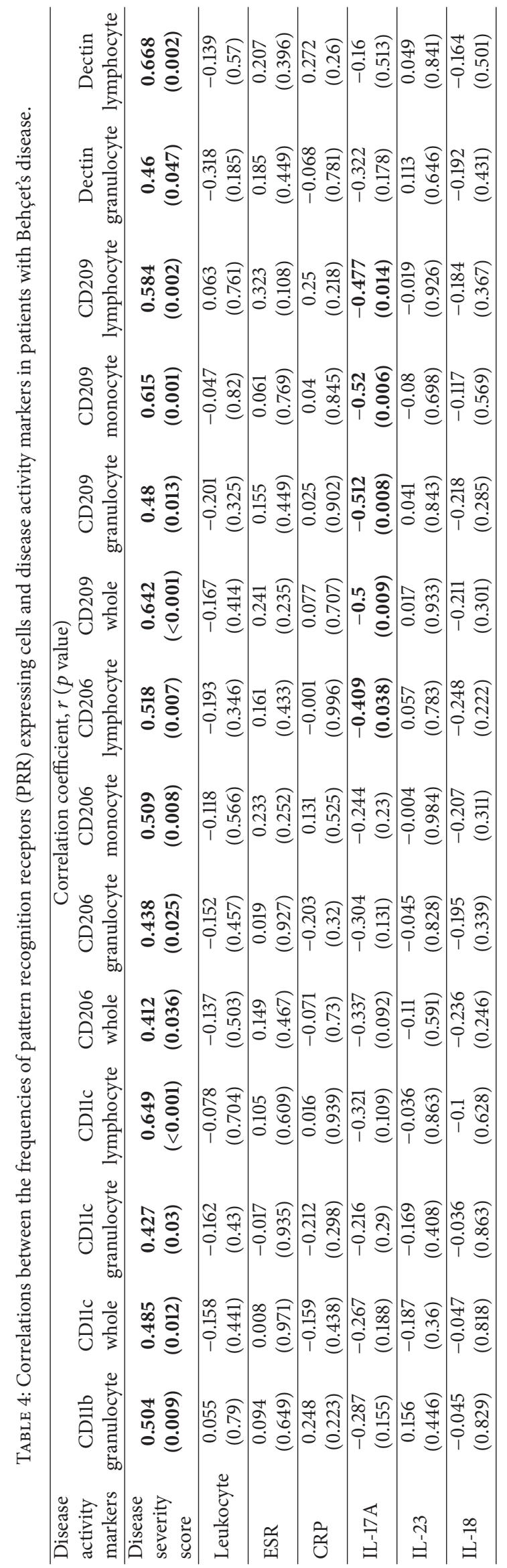


TABLE 5: Correlations between each pattern recognition marker in whole leukocytes of patients with Behçet's disease.

\begin{tabular}{|c|c|c|c|c|c|}
\hline & \multicolumn{5}{|c|}{ Correlation coefficient, $r$ ( $p$ value) } \\
\hline & CD11c & CD32 & CD206 & CD209 & Dectin \\
\hline CD11b & $-0.159(0.438)$ & $0.896(<0.001)$ & $-0.225(0.268)$ & $-0.128(0.534)$ & $0.05(0.839)$ \\
\hline CD11c & & $-0.357(0.074)$ & $0.83(<0.001)$ & $0.677(<0.001)$ & $0.724(<0.001)$ \\
\hline CD32 & & & $-0.439(0.025)$ & $-0.252(0.214)$ & $-0.157(0.521)$ \\
\hline CD206 & & & & $0.679(<0.001)$ & $0.801(<0.001)$ \\
\hline CD209 & & & & & $0.334(0.163)$ \\
\hline
\end{tabular}

Until now, there were no papers regarding CD32 in BD patients. This is the first data describing CD32 in BD patients. In RA patients, CD32 on natural killer (NK) cells were significantly lower than HCs [25]. However, in our results the frequencies of CD32+ cells on whole leukocytes were higher in active BD patients with arthritis than HCs. In RA patients as a disease control, CD32 expressions were not downregulated as compared to HCs. Inactive BD patients were not different as compared to active $\mathrm{BD}$ patients with arthritis. It was reported that CD32 participated in the stimulation of plasmacytoid DC by immune complex combined with anti-DNA antibody in systemic lupus erythematosus [26]. CD32 seems to be involved in the induction of inflammatory responses, but still not enough for defining of the role in inflammation of BD.

The correlation of CD206 and BD has also been rarely reported. There is only one paper for CD206 in BD patients with cutaneous symptoms [27]. CD206 was highly expressed with significance in active BD patients with cutaneous symptoms $(49.7 \pm 35.2 \%)$ compared to inactive BD patients $(4.7 \pm$ $3.1 \%)(p=0.007)$ and HCs $(7.4 \pm 0.8 \%)(p=0.02)$. It is known that CD206 facilitates viral infections such as Dengue virus [28], hepatitis B virus [29], lymphadenopathy associated virus [30], and human immunodeficiency virus [31]. In collagen induced arthritis, CD206 was seen in the inflamed joints by micro-computed tomography imaging [32]. $\mathrm{CD}^{206^{+}}$macrophages were significantly induced in patients with mucosal healing after treatment with infliximab [33]. In the mixed lymphoid reaction, the antibodies against tumor necrosis factor induced CD206+ macrophages. CD206+ macrophages had an immunosuppressive phenotype showing inhibited proliferation of activated T cells [34]. In our results, CD206+ PBMC were downregulated after treatment compared to before treatment in BD patients.

The correlation of CD209 and BD has not been reported at all. Our present study has shown the frequencies of CD209+ cells were significantly decreased in whole leukocytes and monocytes populations after improvement compared to an active symptomatic state. In juvenile idiopathic arthritis, CD209+ cells were increased in peripheral blood and accumulated in synovial fluid [35]. CD209+ cells were also higher in RA synovium than osteoarthritis synovium [36]. CD $209^{+} \mathrm{CD}^{+} 4^{+}$cells were significantly increased in the lesion of lamina propria of Crohn's disease [37]. This subset might be involved in the pathogenesis of Crohn's disease [38].

Dectin-1 has been known to play a role in antifungal immunity [39] for the protection from Candida albicans infection [40] and is involved in the production of arachidonic acid metabolites [41] and DC maturation [42]. Dectin1 recognizes $\beta$-glucans and carbohydrates found in some bacteria and may also recognize other molecules such as endogenous ligand on T cells [43]. Dectin-1 expression is found on myeloid DC, monocytes, macrophages, and B cells [44]. In a genetically arthritis susceptible mouse model, Dectin-1 plays a role for the induction of arthritis [45]. In our experiment, the frequencies of Dectin-1+ cells in granulocytes populations were downregulated after treatment compared to active BD arthritis. Dectin-1 signaling increases the phagocytic activity of neutrophils through upregulation of CD11b expression [46] and increased the production of IL17A. Dectin-1-dependent IL-17A production is mediated by CD11b+ neutrophils in an IL-23 dependent manner [47]. Our data has shown CD11b+Dectin-1+ granulocytes were downregulated after improvement of $\mathrm{BD}$ arthritis though the significance was not different. This is the first data for the Dectin-1 expression in BD.

CD11b+CD206+ macrophages play critical roles in the progression of hepatitis $\mathrm{C}$ virus induced inflammatory liver diseases [48]. In our results, the frequencies of CD11b+CD206+ in whole leukocytes and monocytes were downregulated with improvement of $\mathrm{BD}$ arthritis. Also, $\mathrm{CD} 11 \mathrm{~b}+\mathrm{CD} 32+$ cell populations in whole leukocytes and monocytes were higher in $\mathrm{BD}$ patients compared to $\mathrm{HC}$ irrespective of arthritis activity.

With flow cytometric data, we can conclude the frequencies of CD11b+ and CD32+ cells show similar levels in active and inactive BD. CD11c+, CD206+, CD209+, and Dectin-1 were downregulated after improvement. This means higher levels of CD11b + and CD32+ cells are correlated to the development of BD arthritis. CD11c+, CD206+, CD209+, and Dectin-1 are related to the regulation of $\mathrm{BD}$ symptom. For the therapeutic target, CD11c+, CD206+, CD209+, and Dectin-1 can be more reliable candidates for $\mathrm{BD}$ arthritis. This can be a direction for future experimental plans.

Several papers have shown higher levels of IL-18 in BD patients than HC $[49,50]$. IL-18 with IL-12 or IL-15 enhances the Th1 response, while IL-18 without IL-12 can stimulate Th2 responses [51]. IL-18 with IL-2 or IL-4 enhances the production of IL-4 and IL-13 [52]. In our data, inactive BD patients showed significantly higher IL-18 levels than active BD patients. In $\mathrm{BD}$ patients with arthritis, increased IL-18 in improved stage may have a role for Th2 shift function with IL- 4 or IL-2, even though we did not show the levels of IL-4 or IL-2. 
The serum levels of IL-23 are elevated more in BD patients with active uveitis than HC. BD patients with active uveitis significantly upregulated IL-23 as compared with BD patients without active uveitis [53]. In our data, the levels of IL-23 were higher in $\mathrm{BD}$ patients with arthritis than $\mathrm{HC}$, though the level of IL-23 was not different between active and inactive BD patients. IL-17 was also significantly higher in active BD patients than HC. However, active and inactive BD patients with arthritis showed similar levels of IL-17. Several papers already reported $\mathrm{BD}$ patients with uveitis showed similar levels of IL-17A between active and inactive stage [54, 55]. IL18 gene polymorphism was reported by 5 papers in Turkish, Egyptian, and Korean. These 5 papers did not include the protein levels of IL-18. Oztas et al. reported the increased serum IL-18 protein expression compared to healthy control, but they did not show the comparison between active BD and inactive BD [56]. Musabak et al. reported the serum levels of IL-18 were increased in patients with inactive disease than active disease even though the difference was not significant [57]. They mentioned Thl activation and subclinical inflammation persists during the inactive period of the disease. In our result, similarly to the previous reports, plasma IL-18 levels were higher in active BD than HC. Also, IL-18 in inactive $\mathrm{BD}$ was higher than active BD. According to Habibagahi et al., serum levels of IL-23 were higher in BD with uveitis [58]. IL23 and IL-17 were higher in BD with active uveitis than BD with inactive uveitis [53]. Among this patients population, $33.3 \%$ of patients had arthritis. According to Emiroglu et al., serum IL-17A levels were not different between active BD and inactive BD [55]. This study included 57.9\% articular involvement in cutaneous BD symptomatic patients. They enrolled different populations with and without symptoms instead of chasing the same patients. The expression was similar to our data. In our data, the average levels of IL-23 and IL17 were similar between pretreatment and posttreatment; however, the changes of expression levels are diverse in each patient.

In conclusion, the $\mathrm{CD} 11 \mathrm{~b}+$ and $\mathrm{CD} 32+$ circulating cells were significantly higher in active $\mathrm{BD}$ patients with arthritis than HC. CD1lct and CD209+ cells were significantly decreased after improvement of arthritis in BD patients. Disease severity scores were significantly correlated to the frequencies of CD11b+, CD11c+, CD206+, CD209+, and Dectin-1+ cells. Plasma IL-17A expression levels were also correlated with the frequencies of CD206+ and CD209+ cells. CD206 in monocytes, CD209 in whole cells and monocytes, and $\mathrm{CD} 11 \mathrm{~b}+\mathrm{CD} 206+$ in whole cells and monocytes can be disease activity markers for the improvement of $\mathrm{BD}$ arthritis.

\section{Competing Interests}

The authors declare that there is no conflict of interests regarding the publication of this paper.

\section{Authors' Contributions}

Bunsoon Choi and Chang-Hee Suh contributed equally to this work.

\section{Acknowledgments}

This research was supported by the grant from Basic Science Research Program through the National Research Foundation of Korea (NRF) funded by the Ministry of Education, Science and Technology (2013R1A1A3008248), from the Korea Health Technology R\&D Project through the Korea Health Industry Development Institute (KHIDI), funded by the Ministry of Health \& Welfare, Republic of Korea (HI15C2483), and from the M.D., Ph.D. research fund of Ajou University School of Medicine (M2014C046000129).

\section{References}

[1] T. H. Mogensen, "Pathogen recognition and inflammatory signaling in innate immune defenses," Clinical Microbiology Reviews, vol. 22, no. 2, pp. 240-273, 2009.

[2] O. Takeuchi and S. Akira, "Pattern recognition receptors and inflammation," Cell, vol. 140, no. 6, pp. 805-820, 2010.

[3] R. S. Mahla, M. C. Reddy, D. Vijaya Raghava Prasad, and H. Kumar, "Sweeten PAMPs: role of sugar complexed PAMPs in innate immunity and vaccine biology," Frontiers in Immunology, vol. 4, article 248, 2013.

[4] T. B. H. Geijtenbeek and S. I. Gringhuis, "Signalling through C-type lectin receptors: shaping immune responses," Nature Reviews Immunology, vol. 9, no. 7, pp. 465-479, 2009.

[5] L. Lefèvre, G. Lugo-Villarino, E. Meunier et al., "The Ctype lectin receptors dectin-1, MR, and SIGNR3 contribute both positively and negatively to the macrophage response to Leishmania infantum," Immunity, vol. 38, no. 5, pp. 1038-1049, 2013.

[6] L. Choteau, M. Parny, N. François et al., "Role of mannosebinding lectin in intestinal homeostasis and fungal elimination," Mucosal Immunology, vol. 9, no. 3, pp. 767-776, 2016.

[7] I.-C. Lin, J.-L. Suen, S.-K. Huang et al., "Dectin-1/Syk signaling is involved in Lactobacillus casei cell wall extract-induced mouse model of Kawasaki disease," Immunobiology, vol. 218, no. 2, pp. 201-212, 2013.

[8] C. Salazar-Aldrete, M. Galán-Díez, E. Fernández-Ruiz et al., "Expression and function of dectin-1 is defective in monocytes from patients with systemic lupus erythematosus and rheumatoid arthritis," Journal of Clinical Immunology, vol. 33, no. 2, pp. 368-377, 2013.

[9] J. Kim, C. H. Im, E. H. Kang et al., "Mannose-binding lectin gene-2 polymorphisms and serum mannose-binding lectin levels in Behçet's disease," Clinical and Experimental Rheumatology, vol. 27, no. 2, pp. S13-S17, 2009.

[10] C. E. Bryant, S. Orr, B. Ferguson, M. F. Symmons, J. P. Boyle, and T. P. Monie, "International union of basic and clinical pharmacology. XCVI. Pattern recognition receptors in health and disease," Pharmacological Reviews, vol. 67, no. 2, pp. 462504, 2015.

[11] J. Fang, L. Chen, J. Tang et al., "Association between copy number variations of TLR7 and ocular Behçet's disease in a Chinese Han population," Investigative Ophthalmology and Visual Science, vol. 56, no. 3, pp. 1517-1523, 2015.

[12] N. Seoudi, L. A. Bergmeier, E. Hagi-Pavli, D. Bibby, M. A. Curtis, and F. Fortune, "The role of TLR2 and 4 in Behçet's disease pathogenesis," Innate Immunity, vol. 20, no. 4, pp. 412422, 2014. 
[13] X. Liu, C. Wang, Z. Ye, A. Kijlstra, and P. Yang, "Higher expression of toll-like receptors 2, 3, 4, and 8 in ocular Behcet's disease," Investigative Ophthalmology and Visual Science, vol. 54, no. 9, pp. 6012-6017, 2013.

[14] K. Hamzaoui, H. Abid, A. Berraies, J. Ammar, and A. Hamzaoui, "NOD2 is highly expressed in Behçet disease with pulmonary manifestations," Journal of Inflammation, vol. 9, article no. 3, 2012.

[15] A. K. Oğuz, S. Yilmaz, N. Akar et al., "C-type lectin domain family 12, member A: a common denominator in Behçet's syndrome and acute gouty arthritis," Medical Hypotheses, vol. 85, no. 2, pp. 186-191, 2015.

[16] H. S. de Vries, T. S. Plantinga, J. H. van Krieken et al., "Genetic association analysis of the functional c.714T $>$ G polymorphism and mucosal expression of dectin-1 in inflammatory bowel disease," PLoS ONE, vol. 4, no. 11, Article ID e7818, 2009.

[17] S. Stoppelkamp, D. M. Reid, J. Yeoh et al., "Murine pattern recognition receptor dectin-1 is essential in the development of experimental autoimmune uveoretinitis," Molecular Immunology, vol. 67, no. 2, pp. 398-406, 2015.

[18] O. Martinez, S. Brackenridge, M. E.-A. El-Idrissi, and B. S. Prabhakar, "DC-SIGN, but not sDC-SIGN, can modulate IL2 production from PMA- and anti-CD3-stimulated primary human CD4 T cells," International Immunology, vol. 17, no. 6, pp. 769-778, 2005.

[19] J. Romme Christensen, L. Börnsen, R. Ratzer et al., "Systemic inflammation in progressive multiple sclerosis involves follicular T-helper, Th17- and activated B-cells and correlates with progression," PLoS ONE, vol. 8, no. 3, Article ID e57820, 2013.

[20] M. A. Silva, C. B. López, F. Riverin, L. Oligny, J. Menezes, and E. G. Seidman, "Characterization and distribution of colonic dendritic cells in Crohn's disease," Inflammatory Bowel Diseases, vol. 10, no. 5, pp. 504-512, 2004.

[21] N. Yildirim, N. S. Tekin, I. O. Tekin et al., "Myocardial functional and textural findings of the right and left ventricles and their association with cellular adhesion molecules in Behçet's disease," Echocardiography, vol. 24, no. 7, pp. 702-711, 2007.

[22] J. K. Ahn, H. Chung, D.-S. Lee, Y. S. Yu, and H. G. Yu, "CD8brightCD56+ $\mathrm{T}$ cells are cytotoxic effectors in patients with active Behçet's uveitis," Journal of Immunology, vol. 175, no. 9, pp. 6133-6142, 2005.

[23] S. R. Park, K. S. Park, Y. J. Park, D. Bang, and E.-S. Lee, "CD1la, CD11c, and CD18 gene polymorphisms and susceptibility to Behçet's disease in Koreans," Tissue Antigens, vol. 84, no. 4, pp. 398-404, 2014.

[24] M. Zheng, L. Zhang, H. Yu et al., "Genetic polymorphisms of cell adhesion molecules in Behcet's disease in a Chinese Han population," Scientific Reports, vol. 6, Article ID 24974, 2016.

[25] A. M. Stewart-Akers, A. Cunningham, M. C. Wasko, and P. A. Morel, "Fc $\gamma$ R expression on NK cells influences disease severity in rheumatoid arthritis," Genes and Immunity, vol. 5, no. 7, pp. 521-529, 2004.

[26] T. K. Means, E. Latz, F. Hayashi, M. R. Murali, D. T. Golenbock, and A. D. Luster, "Human lupus autoantibody-DNA complexes activate DCs through cooperation of CD32 and TLR9," Journal of Clinical Investigation, vol. 115, no. 2, pp. 407-417, 2005.

[27] J. A. Shim, S. Cho, D. Bang et al., "Differential expression of monocyte/macrophage markers between active and inactive stage of patients with Behçet's disease," Pathology Discovery, vol. 1, no. 1, article no. 2, 2013.
[28] E. Schaeffer, V. Flacher, V. Papageorgiou et al., "Dermal CD14 dendritic cell and macrophage infection by dengue virus is stimulated by interleukin-4," Journal of Investigative Dermatology, vol. 135, no. 7, pp. 1743-1751, 2015.

[29] K. Dai, L. Huang, X. Sun, L. Yang, and Z. Gong, "Hepatic CD206-positive macrophages express amphiregulin to promote the immunosuppressive activity of regulatory $\mathrm{T}$ cells in HBV infection," Journal of Leukocyte Biology, vol. 98, no. 6, pp. 10711080, 2015.

[30] G. E. Holder, C. M. McGary, E. M. Johnson et al., "Expression of the mannose receptor CD206 in HIV and SIV encephalitis: a phenotypic switch of brain perivascular macrophages with virus infection," Journal of Neuroimmune Pharmacology, vol. 9, no. 5, pp. 716-726, 2014.

[31] Y. Liu, J. Liu, X. Pang, T. Liu, Z. Ning, and G. Cheng, "The roles of direct recognition by animal lectins in antiviral immunity and viral pathogenesis," Molecules, vol. 20, no. 2, pp. 2272-2295, 2015.

[32] S. Put, S. Schoonooghe, N. Devoogdt et al., "SPECT imaging of joint inflammation with nanobodies targeting the macrophage mannose receptor in a mouse model for rheumatoid arthritis," Journal of Nuclear Medicine, vol. 54, no. 5, pp. 807-814, 2013.

[33] A. C. W. Vos, M. E. Wildenberg, I. Arijs et al., "Regulatory macrophages induced by infliximab are involved in healing in vivo and in vitro," Inflammatory Bowel Diseases, vol. 18, no. 3, pp. 401-408, 2012.

[34] A. C. W. Vos, M. E. Wildenberg, M. Duijvestein, A. P. Verhaar, G. R. van den Brink, and D. W. Hommes, "Anti-tumor necrosis factor- $\alpha$ antibodies induce regulatory macrophages in an Fc region-dependent manner," Gastroenterology, vol. 140, no. 1, pp. 221-230, 2011.

[35] J. Tabarkiewiez, J. Postepski, E. Olesińska, J. Roliński, and E. Tuszkiewicz-Misztal, "Identification of dendritic cells in the blood and synovial fluid of children with juvenile idiopathic arthritis," Folia Histochemica et Cytobiologica, vol. 49, no. 1, pp. 188-199, 2011.

[36] P. L. E. M. Van Lent, C. G. Figdor, P. Barrera et al., "Expression of the dendritic cell-associated C-type lectin DC-SIGN by inflammatory matrix metalloproteinase-producing macrophages in rheumatoid arthritis synovium and interaction with intercellular adhesion molecule 3-positive T cells," Arthritis and Rheumatism, vol. 48, no. 2, pp. 360-369, 2003.

[37] N. Kamada, T. Hisamatsu, H. Honda et al., "Human CD14+ macrophages in intestinal lamina propria exhibit potent antigen-presenting ability," Journal of Immunology, vol. 183, no. 3, pp. 1724-1731, 2009.

[38] N. Kamada, T. Hisamatsu, S. Okamoto et al., "Unique CD14+ intestinal macrophages contribute to the pathogenesis of Crohn disease via IL-23/IFN- $\gamma$ axis," Journal of Clinical Investigation, vol. 118, no. 6, pp. 2269-2280, 2008.

[39] M. J. Marakalala, S. Vautier, J. Potrykus et al., "Differential adaptation of Candida albicans in vivo modulates immune recognition by dectin-1," PLoS Pathogens, vol. 9, no. 4, Article ID e1003315, 2013.

[40] X. Li, A. Utomo, X. Cullere et al., "The $\beta$-glucan receptor dectin1 activates the integrin Mac-1 in neutrophils via vav protein signaling to promote Candida albicans clearance," Cell Host and Microbe, vol. 10, no. 6, pp. 603-615, 2011.

[41] I. Valera, N. Fernández, A. G. Trinidad et al., "Costimulation of dectin-1 and DC-SIGN triggers the arachidonic acid cascade in human monocyte-derived dendritic cells," Journal of Immunology, vol. 180, no. 8, pp. 5727-5736, 2008. 
[42] A. Dragicevic, T. Dzopalic, S. Vasilijic et al., "Signaling through Toll-like receptor 3 and Dectin-1 potentiates the capability of human monocyte-derived dendritic cells to promote T-helper 1 and T-helper 17 immune responses," Cytotherapy, vol. 14, no. 5, pp. 598-607, 2012.

[43] R. A. Drummond and G. D. Brown, "The role of Dectin-1 in the host defence against fungal infections," Current Opinion in Microbiology, vol. 14, no. 4, pp. 392-399, 2011.

[44] G. D. Brown, "Dectin-1: a signalling non-TLR patternrecognition receptor," Nature Reviews Immunology, vol. 6, no. 1, pp. 33-43, 2006.

[45] H. Yoshitomi, N. Sakaguchi, K. Kobayashi et al., "A role for fungal $\beta$-glucans and their receptor Dectin-1 in the induction of autoimmune arthritis in genetically susceptible mice," The Journal of Experimental Medicine, vol. 201, no. 6, pp. 949-960, 2005.

[46] H. T. Le, V. G. Tran, W. Kim, J. Kim, H. R. Cho, and B. Kwon, "IL33 priming regulates multiple steps of the neutrophil-mediated anti-Candida albicans response by modulating TLR and dectin1 signals," The Journal of Immunology, vol. 189, no. 1, pp. 287-295, 2012.

[47] J. L. Werner, M. A. Gessner, L. M. Lilly et al., "Neutrophils produce interleukin 17A (IL-17A) in a Dectin-1- and IL-23dependent manner during invasive fungal infection," Infection and Immunity, vol. 79, no. 10, pp. 3966-3977, 2011.

[48] T. Ohtsuki, K. Kimura, Y. Tokunaga et al., "M2 macrophages play critical roles in progression of inflammatory liver disease in hepatitis C virus transgenic mice," Journal of Virology, vol. 90, no. 1, pp. 300-307, 2016.

[49] G. Lopalco, O. M. Lucherini, A. Vitale et al., "Putative role of serum amyloid-A and proinflammatory cytokines as biomarkers for behcet's disease," Medicine (United States), vol. 94, no. 42, 2015.

[50] K. Ozyurt, A. Çelik, M. Sayarlioglu et al., "Serum Th1, Th2 and Th17 cytokine profiles and alpha-enolase levels in recurrent aphthous stomatitis," Journal of Oral Pathology and Medicine, vol. 43, no. 9, pp. 691-695, 2014.

[51] J. H. Lee, D. H. Cho, and H. J. Park, "IL-18 and cutaneous inflammatory diseases," International Journal of Molecular Sciences, vol. 16, no. 12, pp. 29357-29369, 2015.

[52] H. Mühl and J. Pfeilschifter, "Interleukin-18 bioactivity: a novel target for immunopharmacological anti-inflammatory intervention," European Journal of Pharmacology, vol. 500, no. 1-3, pp. 63-71, 2004.

[53] W. Chi, X. Zhu, P. Yang et al., "Upregulated IL-23 and IL-17 in Behçet patients with active uveitis," Investigative Ophthalmology and Visual Science, vol. 49, no. 7, pp. 3058-3064, 2008.

[54] M. Mesquida, B. Molins, V. Llorenç et al., "Proinflammatory cytokines and c-reactive protein in uveitis associated with Behçet's disease," Mediators of Inflammation, vol. 2014, Article ID 396204, 8 pages, 2014.

[55] N. Emiroglu, F. P. Cengiz, and G. B. Erdem, "Serum IL-17A in Behçet's disease," Postępy Dermatologii i Alergologii, vol. 32, no. 5, pp. 358-361, 2015.

[56] M. O. Oztas, M. Onder, M. A. Gurer, N. Bukan, and B. Sancak, "Serum interleukin 18 and tumour necrosis factor- $\alpha$ levels are increased in Behçet's disease," Clinical and Experimental Dermatology, vol. 30, no. 1, pp. 61-63, 2005.

[57] U. Musabak, S. Pay, H. Erdem et al., "Serum interleukin-18 levels in patients with Behçet's disease. Is its expression associated with disease activity or clinical presentations?" Rheumatology International, vol. 26, no. 6, pp. 545-550, 2006.
[58] Z. Habibagahi, M. Habibagahi, and M. Heidari, "Raised concentration of soluble form of vascular endothelial cadherin and IL-23 in sera of patients with Behçet's disease," Modern Rheumatology, vol. 20, no. 2, pp. 154-159, 2010. 


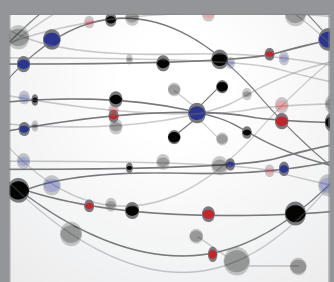

The Scientific World Journal
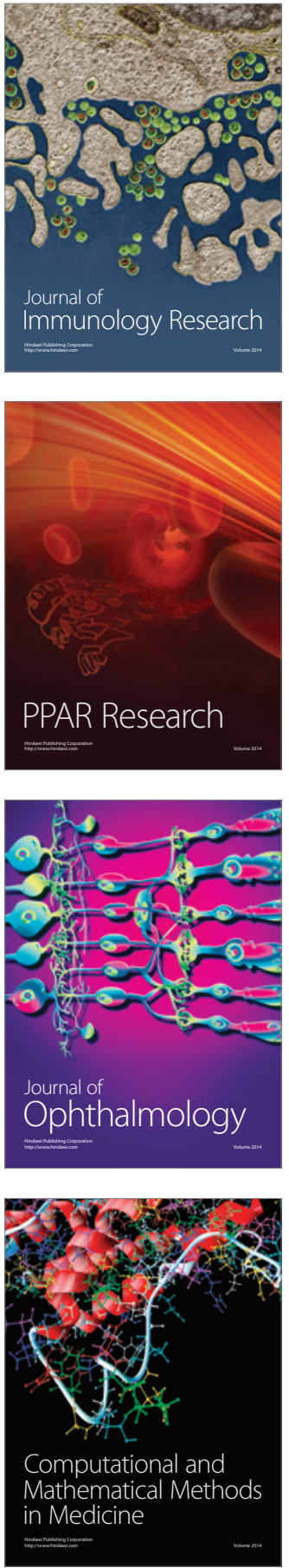

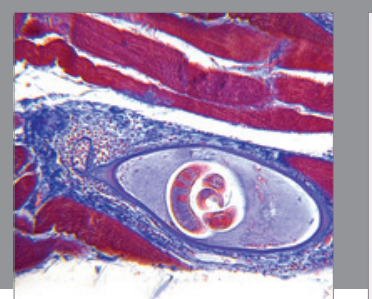

Gastroenterology Research and Practice
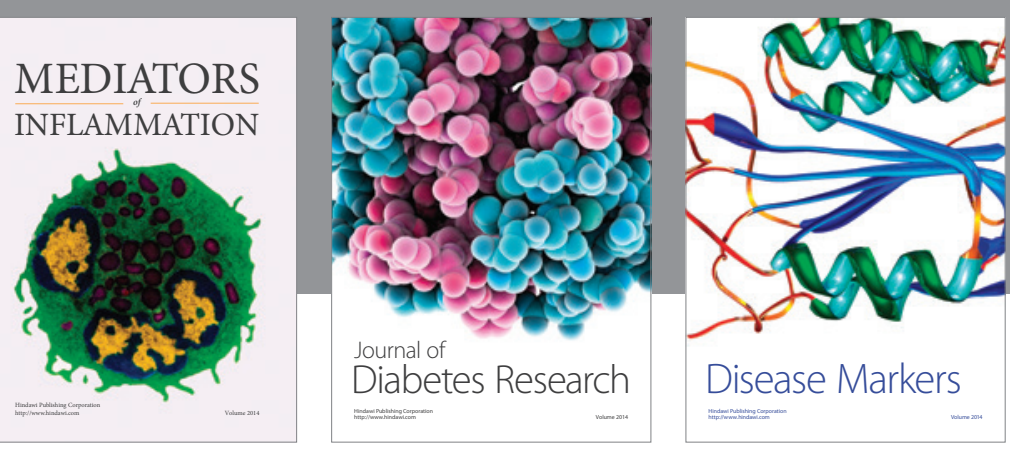

Disease Markers

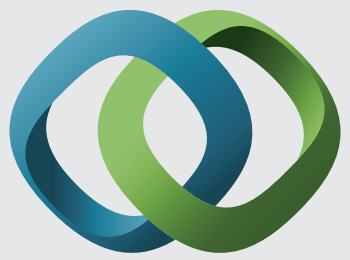

\section{Hindawi}

Submit your manuscripts at

https://www.hindawi.com
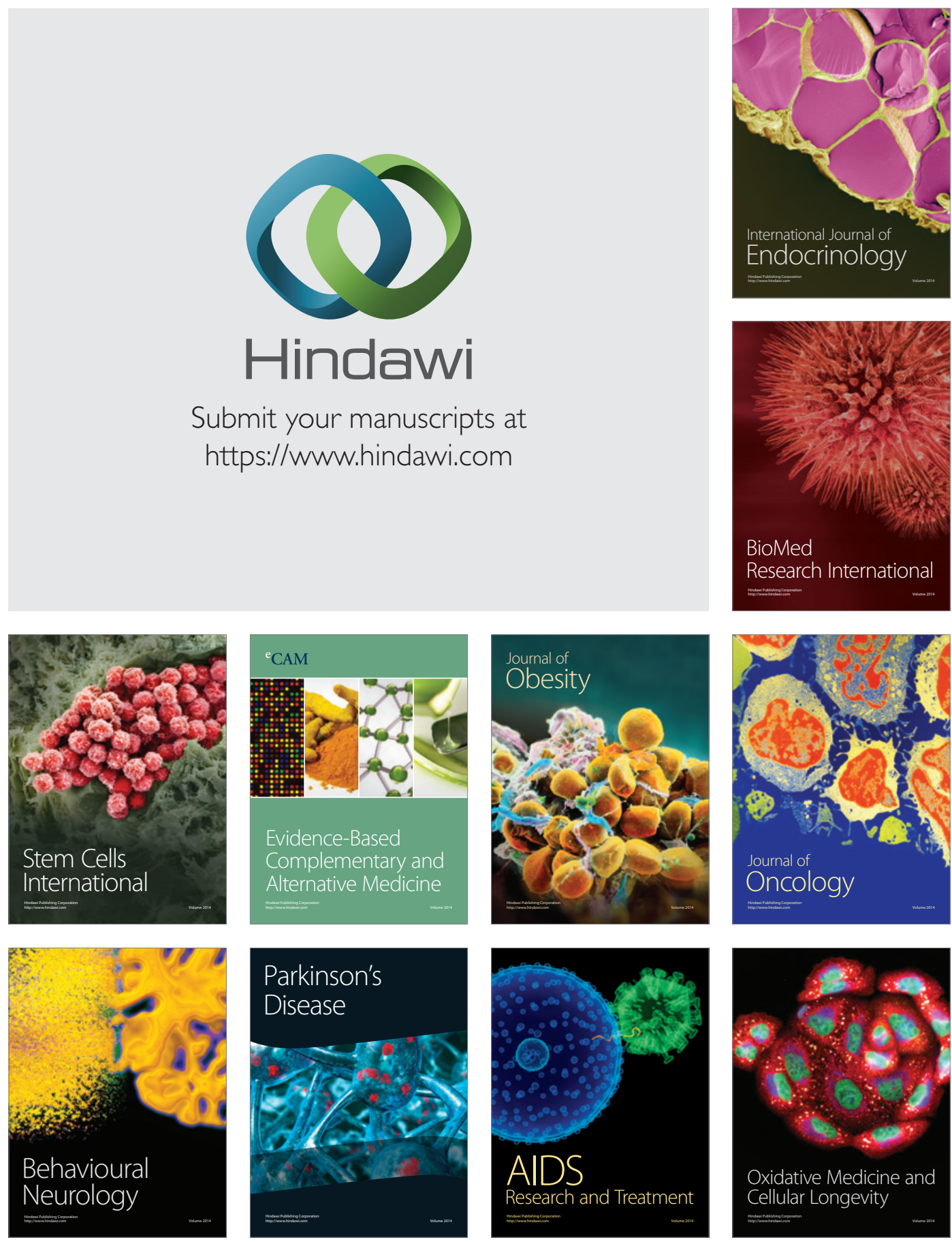